\title{
Seasonal influence on the thyroid gland in healthy dogs of various breeds in different weights
}

\author{
Mária Fialkovičová1, Silvia Mardzinová1, Marta Benková2 ${ }^{2}$ Jana Mojžišováa \\ Monika Gaálová ${ }^{1}$, Edina Sesztáková ${ }^{4}$ \\ ${ }^{1}$ Small Animal Clinic , University of Veterinary Medicine and Pharmacy, Košice, Slovak Republic \\ ${ }^{2}$ Technical University of Košice, Institute of Control and Informatization of Production Processes, \\ Košice, Slovak Republic \\ ${ }^{3}$ Department of Epizootology and Parasitology , \\ ${ }^{4}$ Clinic of Birds, Exotic and Free-living Animals, University of Veterinary Medicine and Pharmacy, \\ Košice, Slovak Republic \\ Received February 19, 2010 \\ Accepted March 7, 2012
}

\begin{abstract}
The aim of our study was to evaluate the influence of seasonal ambient temperature on the thyroid gland function in terms of serum total thyroxine (TT4), free thyroxine (fT4), total triiodothyronine (TT3), and canine thyroid stimulating hormone (cTSH) concentrations in healthy dogs of various breeds living outdoors and to compare them with those living indoors in flats and houses. The monitoring was conducted for 5 years and our study included 162 indoor dogs and 148 outdoor dogs of both sexes from 2 to 12 years of age, categorised into 3 groups according to their body weight: large $(n=17)$, medium $(n=16)$ and small $(n=17)$ breeds. Comparison of the seasonal serum TT4 and fT4 concentrations in both the indoor and outdoor dogs confirmed their fluctuation in relation to the ambient temperature in all weight groups with the lowest average of TT4 and fT4 concentrations recorded in summer and the highest ones in winter. In dogs kept outdoors, the fluctuation of hormone values was significant $(P<0.05)$. Seasonal serum cTSH fluctuation was found to be significant $(P<0.05)$ only in the medium breeds living outdoors, but their concentrations did not exceed the reference ranges. The 5-year monitoring of serum TT3 in indoor and outdoor dogs of large, medium, and small breeds clearly showed that its concentrations were not influenced by varying ambient temperature. The study provides for the first time evidence that serum TT4 and fT4 concentrations in dogs kept outdoors directly depend on ambient temperature. This correlation was also expressed by mathematical equations.
\end{abstract}

Dog, ambient temperature, thyroxine, thyreotropine

Thyroid hormones influence numerous physiological and biochemical events in cells, and are essential for healthy growth and development of neurological and skeletal systems. They have catabolic effects on muscle and adipose tissue and regulate cholesterol synthesis and degradation. Thyroid hormones have positive ionotropic and chronotropic effects on the heart (Scott-Moncrieff 2007). Thyroid hormones markedly stimulate $\mathrm{Na}^{+} \mathrm{K}^{+} \mathrm{ATP}-$ ase activity, which is connected to $\mathrm{Na}^{+}$and $\mathrm{K}^{+}$transport through the plasma membrane (Schaafsma et al. 2002; Slob et al. 2004). This process increases ATP utilisation. As a great part of oxygen consumption in the whole organism maintaining this transport system, the principal effect of the thyroid gland on the basal metabolism is expected to be correlated exactly with this effect. Thyroid hormones increase the metabolic rate and oxygen consumption of most tissues, with the exception of the adult brain, testes, uterus, lymph nodes, spleen and anterior pituitary (Fergus on 1988; Freake and Oppenheimer 1995). They increase the 2,3-diphosphoglycerate production in erythrocytes, which facilitates oxygen release from haemoglobin and they stimulate the generation of heat. This supports the hypothesis that total thyroxine concentrations should vary in relation to ambient temperature and should reflect seasonal variation, too (Freake and Oppenheimer 1995).

Address for correspondence:

Mária Fialkovičová

Small Animal Clinic

University of Veterinary Medicine and Pharmacy

Phone: +421915986681

Komenského 73, 04181 Košice, Slovak Republic 
The aim of our study was to perform a comparative analysis of the influence of seasonal ambient temperature on the thyroid gland function, by measurement of serum total thyroxine (TT4), free thyroxine (fT4), total triiodothyronine (TT3), and canine thyroid stimulating hormone (cTSH) concentrations in healthy dogs of various breeds living outdoors and indoors in flats and houses.

\section{Materials and Methods}

Our study monitored TT4, fT4, cTSH and TT3 concentrations in serum of 310 healthy dogs of both sexes at the age of 2 to 12 years. The dogs were in private ownership. The study lasted from 2004 to 2008. Classification of dogs as healthy was based on their history, physical examination, complete blood count, biochemistry and endocrinological profile. According to the body condition score, lean and obese dogs (grade 1, 4 and 5) were excluded from the study. Females with serum progesterone concentrations exceeding $0.5 \mathrm{ng} / \mathrm{ml}$ were excluded, too. Dogs were divided into 3 groups based on their body weight. Dogs weighing over $27 \mathrm{~kg}$ were classified as a large group $(\mathrm{n}=110)$, dogs with the body weight ranging from $12 \mathrm{~kg}$ to $27 \mathrm{~kg}$ were included in the medium group $(\mathrm{n}=89)$ and dogs with a body weight below $12 \mathrm{~kg}(\mathrm{n}=111)$ represented the small group.

Each group was subdivided into dogs kept outdoors throughout the year and dogs kept indoors in flats and houses. Groups of dogs based on their body weight, breed, indoor or outdoor keeping and their numbers are shown in Table 1. Dogs kept indoors were exercised 2-4 × per day, but spent most of the day and the whole night in flats or houses. All dogs were fed a standard commercial dry food twice a day. No dog included in the study received medication apart from routine flea and worm control products. Standard health checks and serological tests were carried out in each dog twice a year and at annual vaccination.

Table 1. List of dogs used in our study (large, medium and small breeds living indoors and outdoors and their numbers).

\begin{tabular}{|c|c|c|c|c|c|c|c|c|}
\hline $\begin{array}{l}\text { Large } \\
n=110\end{array}$ & $\frac{\mathscr{E}}{5}$ & $\frac{\stackrel{\theta}{0}}{\stackrel{0}{0}}$ & $\begin{array}{l}\text { Medium } \\
\mathrm{n}=89\end{array}$ & 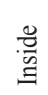 & $\frac{\stackrel{0}{0}}{0}$ & $\begin{array}{l}\text { Small } \\
\mathrm{n}=111\end{array}$ & $\stackrel{\mathscr{D}}{\mathscr{n}}$ & 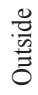 \\
\hline Alaskan Malamut & 0 & 3 & American Cocker Spaniel & 5 & 0 & Cavalier King Charles Spaniel & 2 & 0 \\
\hline Belgian Shepherd & 1 & 0 & American Staffordshire Terrier & 2 & 0 & Dachshund & 8 & 15 \\
\hline Bernese Mountain Dog & 0 & 2 & Beagle & 2 & 4 & Deutscher Pinscher & 4 & 0 \\
\hline Briard & 1 & 0 & Pit Bull & 1 & 0 & Fox Terrier Wire & 1 & 1 \\
\hline Dobermann & 8 & 0 & Bull Terrier & 3 & 0 & French Bulldog & 2 & 1 \\
\hline English Mastiff & 1 & 0 & Collie & 0 & 2 & Japanese Chin & 1 & 0 \\
\hline German Shephard & 13 & 25 & Dalmatian & 1 & 1 & Lhasa-apso & 2 & 0 \\
\hline Giant Schnauzer & 2 & 2 & Deutscher Spitz & 2 & 6 & Maltese & 4 & 0 \\
\hline Golden Retriever & 7 & 5 & English Cocker Spaniel & 21 & 11 & Miniature Deutscher Spitz & 4 & 16 \\
\hline Irish Wolfhund & 1 & 1 & English Springer Spaniel & 3 & 0 & Miniature Schnauzer & 0 & 1 \\
\hline Labrador relriever & 7 & 7 & German Wired Hair Pointer & 0 & 5 & Mixed & 0 & 15 \\
\hline Mixed & 4 & 1 & Chow Chow & 0 & 1 & Pekingese & 5 & 0 \\
\hline Newfoundland & 0 & 1 & Kerry Blue Terrier & 3 & 0 & Poodle & 17 & 0 \\
\hline Rhodesian Ridgeback & 3 & 0 & Mixed & 2 & 12 & Pug & 2 & 0 \\
\hline Rotweiler & 5 & 2 & Shar-Pei & 1 & 0 & Welsh Terrier & 2 & 0 \\
\hline Siberian Husky & 0 & 5 & Tibetan Terrier & 1 & 0 & West Highland White Terrier & 3 & 0 \\
\hline Slovak Cuvac & 0 & 3 & & & & Yorkshire Terrier & 5 & 0 \\
\hline Total & 53 & 57 & Total & 47 & 42 & Total & 62 & 49 \\
\hline
\end{tabular}

In indoor and outdoor dogs, serum TT4, fT4, cTSH and TT3 concentrations were monitored in every season in relation to the ambient temperature. Official data for monthly average ambient temperatures were obtained from the Meteorological Institute of the Slovak Academy of Science for years 2004-2008. While the average spring and summer ambient temperatures rose to $10.2^{\circ} \mathrm{C}$ and $19.8^{\circ} \mathrm{C}$, respectively, the autumn and winter average ambient temperatures inland were $9.82^{\circ} \mathrm{C}$ and $-0.35^{\circ} \mathrm{C}$, respectively (latitude $48.4{ }^{\circ} \mathrm{N}$ ).

In most cases, blood samples were collected by venipuncture of v. cephalica antebrachii between $10.00 \mathrm{~h}$ and $14.00 \mathrm{~h}$ after 12 -h fasting. 
Serum TT4, fT4 and TT3 concentrations were measured using radioimmunoassay and serum cTSH concentration by immunoradiometric assay validated for the use on serum from dogs (Coat-A-Count Canine TSH, IRMA, Diagnostic Products, Los Angeles, California). Two-way ANOVA was used for statistical comparison of the basal serum TT4 or fT4 and cTSH concentration between breeds with seasonal dependency. The value of $P<0.05$ was considered significant. One-way ANOVA was used for comparison of TT4, FT4 and cTSH concentrations in relation to age of various dog breeds.

\section{Results}

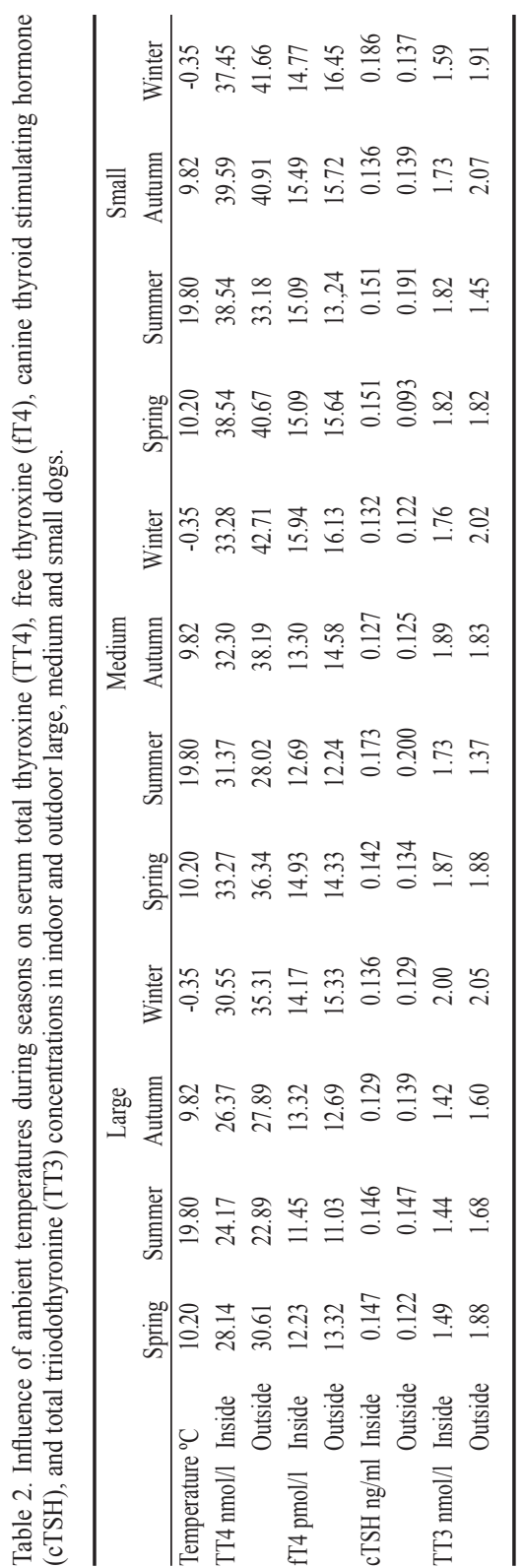

The average serum TT4 concentrations 29.11 $\mathrm{nmol} / \mathrm{l}, 36.31 \mathrm{nmol} / \mathrm{l}$ and $39.11 \mathrm{nmol} / \mathrm{l}$ in dogs of large, medium and small breeds kept outdoors, respectively, were higher than those in dogs kept indoors in the same weight groups (27.31 nmol/1, $32.55 \mathrm{nmol} / 1,38.53 \mathrm{nmol} / 1$, respectively). Comparison of the average TT4 concentrations in various breeds of dogs confirmed the tendency to higher concentrations in medium and small breeds of dogs compared with large breeds. Differences in mean concentrations of serum TT4 in relation to breed size were confirmed as significant $(P<0.05)$ in dogs kept both indoors and outdoors. Comparison of serum TT4 concentrations during seasons in dogs kept indoors and outdoors confirmed their fluctuation in relation to the ambient temperature in all weight groups (Table 2 ). This fluctuation was more marked in outdoor dogs, with the lowest average TT4 concentrations (22.89 nmol/1, $28.02 \mathrm{nmol} / 1$ and $33.18 \mathrm{nmol} / \mathrm{l}$ ) in large, medium and small breeds of dogs, respectively, recorded in summer and the highest in winter $(35.31 \mathrm{nmol} / 1,42.71 \mathrm{nmol} / \mathrm{l}, 41.66$ $\mathrm{nmol} / \mathrm{l}$, respectively). Comparison of seasonally dependent serum TT4 concentrations between weight groups of dogs kept outdoors confirmed significance $(P<0.05)$.

Analysis of mean serum fT4 concentrations in outdoor dogs of large (13.09 pmol/1), medium (14.32 pmol/l) and small breeds (15.26 pmol/1) showed higher concentrations in comparison with indoor dogs in the same weight groups (12.79 nmol/1, $14.21 \mathrm{nmol} / 1$, and $15.11 \mathrm{nmol} / 1$, respectively). This monitoring of mean serum fT4 concentrations in the weight groups of dogs showed a tendency to the higher levels in medium and small breeds in contrast to large ones. Dependency of fT4 concentrations on the breed size was found to be significant in both indoor and outdoor dogs $(P<0.05)$. Fluctuation of fT4 was confirmed in indoor and outdoor dogs throughout the year in all weight groups in relation to ambient temperature (Table 2). In outdoor dogs, the lowest fT4 concentrations in all breeds was found in 
summer (11.03 pmol/1, $12.24 \mathrm{pmol} / 1$ and $13.24 \mathrm{pmol} / \mathrm{l}$, respectively) and the highest in winter (15.33 pmol/1, $16.13 \mathrm{pmol} / 1$, and $16.45 \mathrm{pmol} / \mathrm{l}$, respectively). Significant seasonal serum fT4 fluctuation in outdoor dogs was recorded with significant differences in fT4 concentrations in relation to ambient temperatures $(P<0.05)$.

Evaluation of mean serum cTSH concentrations in large $(0.134 \mathrm{pg} / \mathrm{ml})$, medium $(0.145$ $\mathrm{pg} / \mathrm{ml})$ and small breeds $(0.140 \mathrm{pg} / \mathrm{ml})$ of outdoor dogs did not reveal any significant differences in their concentrations when compared with indoor dogs of the same weight groups $(0.139 \mathrm{pg} / \mathrm{ml}, 0.143 \mathrm{pg} / \mathrm{ml}$, and $0.156 \mathrm{pg} / \mathrm{ml}$, respectively). The comparative analysis of the serum cTSH concentrations during seasons in indoor and outdoor dogs revealed mild seasonal fluctuation in relation to the ambient temperature mainly in outdoor dogs of medium breeds as showed in Table 2. Fluctuation of the serum cTSH concentrations from season to season was considered significant in outdoor dogs $(P<0.05)$.

Monitoring of serum TT3 in indoor and outdoor dogs of large, medium and small breeds clearly showed that their concentrations are not influenced either by breed size or by seasonally varying ambient temperature (Table 2). Statistical analysis did not confirm any significant differences in the TT3 concentrations either between weight groups or interseasonally.

Table 3 shows the summary results of statistical analysis for TT4, fT4, cTSH and TT3 in indoor and outdoor dogs of large, medium and small breeds.

Table 3. Summary results of Two-way Analysis of Variance for thyroxine (TT4), free thyroxine (fT4), canine thyroid stimulating hormone (cTSH) and total triiodothyronine (TT3) in indoors and outdoors dogs of large, medium and small breeds.

\begin{tabular}{lcccccccc}
\hline & Inside & Outside & Inside & Outside & Inside & Outside & Inside & Outside \\
\hline & TT4 & & fT4 & & cTSH & & TT3 & \\
Season & - & + & - & + & - & + & - & - \\
Breed size & + & + & + & + & - & - & - & - \\
\hline
\end{tabular}

+ indicates significance $(P<0.05)$ in relation to season and breed size

Our results from monitoring the serum TT4, fT4 and cTSH concentrations revealed a significant relationship between concentration peak and ambient temperature in outdoor dogs. Therefore, we carried out further tests of correlation coefficients on these outdoor dogs and calculated equations of serum TT4, fT4 and cTSH concentrations in relation to ambient temperature (t) (Table 4). Values of correlation coefficients of serum TT4 and fT4 concentrations confirmed significant negative dependency in large $(r=-0.640$ and -0.727$)$, medium $(r=-0.672$ and -0.473$)$ and small breeds of $\operatorname{dogs}(r=-0.609$ and -0.400$)$ on ambient temperature (Table 4). Serum cTSH concentrations correlated significantly with ambient

Table 4. Influence of total thyroxine (TT4), free thyroxine (fT4), and canine thyroid stimulating hormone (cTSH) on ambient temperature in outdoor dogs of large, medium and small breeds and their correlation coefficients.

\begin{tabular}{lllll}
\hline & & TT4 & fT4 & cTSH \\
\hline Large & Equation & TT4 $=34.701-0.520 . \mathrm{t}$ & fT4 $=15.049-0.190 . \mathrm{t}$ & $\mathrm{cTSH}=0.121+0.001 . \mathrm{t}$ \\
& Correlation coefficient & -0.640 & -0.727 & 0.159 \\
\multirow{2}{*}{ Medium } & Equation & TT4 $=43.793-0.645 . \mathrm{t}$ & $\mathrm{fT} 4=16.194-0.161 . \mathrm{t}$ & $\mathrm{cTSH}=0.106+0.0035 . \mathrm{t}$ \\
& Correlation coefficient & -0.672 & -0.473 & 0.353 \\
& Equatl & TT4 $=43.703-0.400 . \mathrm{t}$ & $\mathrm{fT} 4=16.181-0.147 . \mathrm{t}$ & $\mathrm{cTSH}=0.115+0.003 . \mathrm{t}$ \\
& Correlation coefficient & -0.609 & -0.400 & 0.251 \\
\hline
\end{tabular}

$\mathrm{t}$ - actual ambient temperature 
temperature but only in medium breeds of dogs. Reported equations allow calculating physiological serum TT4, fT4 and cTSH concentrations in healthy dogs after substituting the value of ambient temperature (t) (Table 4).

\section{Discussion}

Thyroid hormone secretion is essential for the postnatal development of neural and skeletal systems, for the organism's growth and appropriate degree of metabolic activity, including generation and release of energy. Consequently, concentrations of these hormones are higher during growth and development than in maturity (Reimers et al. 1990; Freak and Oppenheimer 1995). Fergus on (1988) published the results of studies confirming that the highest concentrations of total thyroxine (TT4) occur in puppyhood and that a marked decline in its concentration occurs from 3 to 9 years of age, with a subsequent rise in TT4 concentration. Although his results were obtained from only one dog breed, namely Beagles, similar results have been published by other authors (Hoh and Oh 2006; Ferm et al. 2009).

In our study, we focused on dogs aged from 2-12 years in order to have a homogenous group of healthy animals whose serum thyroid concentrations could not be influenced by young age.

Physiological TT4 concentrations in small breeds of dogs are generally higher than those in medium or large breeds (Reimers et al. 1990; Feldman and Nelson 2004; Lee et al. 2004). We also found significant differences in TT4 and fT4 concentrations between breeds; large breeds were confirmed to have lower serum thyroid hormone concentrations than medium and small breeds in both dogs kept outdoors and indoors. Serum TT3 and cTSH were not influenced by breed size.

Many authors described specific differences in TT4 and fT4 concentrations in different breeds of dogs. Panciera (1997) reported that sighthounds have much lower serum TT4 concentrations than most other breeds, frequently within the hypothyroid range. Studies of Greyhounds have shown that they have their basal TT4 concentrations below the non-breed-specific reference range, and that their fT4 concentrations are also relatively low, although not to the same degree as TT4. No significant differences were detected between the concentrations of cTSH in Greyhounds and other breeds (Hill et al. 2001; Gaughan and Bruyette 2001). Similar results were also found in Whippets, where the mean TT4 values were significantly lower in comparison to the control group, but no significant differences were seen between Whippets and control dogs for fT4 and cTSH (Geffen et al. 2006). A study evaluating the thyroid status in Basenjis in Australia documented a similar reference range for the serum TSH but a considerably lower reference range for TT4 than in most breeds, resembling the sighthounds in this respect (Seavers et al. 2008). To get over breed differences in the serum thyroid hormone concentrations a sufficient number of breeds were included to our study that would reflect the normal interbred variation within the dog population in Slovakia. The observed dogs were divided into 3 weight groups with respect to the differences in the thyroid hormone concentrations according to breed size.

Many studies documented also other factors influencing serum thyroid hormone concentrations including latitude, circadian rhythm and seasonal changes (Oohashi et al. 2001; Hoh and Oh 2006; Dunlap et al. 2008). There were interesting results, although samples were relatively small. Oohashi et al. (2001) monitored monthly fluctuation of serum TT4, fT4 and cTSH concentrations for one year. They compared their results with those from monitoring a larger sample of German Shepherds and Dachshunds whose serum TT4 concentrations correlated with ambient temperatures, the highest being in winter and the lowest in summer (Tučková et al. 1995). Conversely, the above mentioned monitoring of Beagles recorded the lowest serum TT4 concentrations in January and the highest in March, August and September. The author claimed that fT4 measurement should represent the thyroid function more accurately 
than TT4 monitoring and suggests that in Beagles the highest fT4 concentrations was recorded in January and November as a reaction to the decreased ambient temperature by increasing of the basal metabolic rate.

Monitoring of basal cTSH concentrations in different months did not reveal seasonal dependency (Oohashi et al. 2001). Seasonal serum cTSH fluctuation in our study was found to be significant only in the medium breeds living outdoors, but their concentrations did not exceed the reference range $0-0.4 \mathrm{ng} / \mathrm{ml}$ (Boretti and Reusch 2004).

In summary, we can state that serum TT4 and fT4 concentrations showed seasonal dependence in both outdoor and indoor dogs of all breeds. In dogs kept outdoors, this fluctuation was significant and quantifiably dependent on ambient temperature. Statistical analysis confirmed a negative correlation with the ambient temperature in dogs kept outdoors. Reported equations found in Table 4 allow calculating physiological serum TT4, fT4 and cTSH concentrations in healthy dogs after substituting the value of ambient temperature $(\mathrm{t})$.

\section{Acknowledgement}

The article was supported by project VEGA 1/0351/08

\section{References}

Boretti FS, Reusch CE 2004: Endogenous TSH in the diagnosis of hypothyroidism in dogs. Schweiz Arch Tierheilkd 146: 183-186

Dunlap KL, Reynolds JA, Refsal RK, Kerr WW, Duffy LK 2008: Cross-latitudinal, seasonal and diurnal comparisons in thyroid hormone concentrations in sled dogs. Am J Anim Vet Sci 3: 96-103

Feldman EC, Nelson RW 2004: Canine hypothyroidism. In: Feldman EC, Nelson RW: Canine and feline endocrinology and reproduction. W.B. Saunders St. Louis, pp. 86-151

Ferguson DC 1988: The effect of nonthyroidal factors on thyroid function test in dogs. Compend Cont Educ Pract Vet 10: 1365-1377

Ferm K, Bjornefeldt S, Karlsson A, Andersson G, Nachreiner P, Hedhammar A 2009: Prevalence of diagnostic characteristics indicating canine autoimmune lymphocytic thyroiditis in giant schnauzers and hovawart dogs. J Small Anim Pract 50: 176-179

Freak HC, Oppenheimer JH 1995: Thermogenesis and thyroid function. Annu Rev Nutr 15: 263-291

Gaughan KR, Bruyette DS 2001: Thyroid function testing in Greyhounds. Am J Vet Res 62: 1130-1133

Geffen C, Bavegems V, Duchateau L, Roover K, Dainet S 2006: Serum thyroid hormone concentrations and thyroglobulin autoantibodies in trained and non-trained healthy whippets. Vet J 172: 135-140

Hill RC, Fox LE, Lewis DD, Beale KA, Nachreiner RE, Scott KC, Sundstrom DA, Jones GL, Butterwick RF 2001: Effects of racing and training on serum thyroid hormone concentrations in racing Greyhounds. Am J Vet Res 62: 1969-1972

Hoh WP, Oh TH 2006: Circadian variations of serum thyroxine, free thyroxine and 3,5,3' triiodothyronine concentrations in healthy dogs. J Vet Sci 7: 25-29

Lee JA, Kenneth, WH, Piercsy JR, Schmidt, KE, Nelson Jr S 2004: Effects of racing and nontraining on plasma thyroid hormone concentrations in sled dogs. J Am Vet Med Assoc 224: 226-231

Oohashi E, Yagi K, Uzuka Y, Tanabe S, Sharashina T, Ishida T 2001: Seasonal changes in serum total thyroxine, free thyroxine and canine thyroid response hormone in clinically healthy beagles in Hokkaido. J Vet Med Sci 63: $1241-1243$

Panciera DL 1997: Thyroid-function testing: Is the future here? Vet Med 92: 50-57

Reimers TJ, Lawler DF, Setaria PM, Correa MT, Erb HN 1990: Effects of age, sex, and body size on serum concentrations of thyroid and adrenocortical hormones in dogs. Am J Vet Res 51: 454-457

Scott-Moncrieff JC 2007: Clinical signs and concurrent diseases of hypothyroidism in dogs and cats. Vet Clin Small Anim 37: 709-722

Seavers A, Snow DH, Mason KV, Malik R 2008: Evaluation of the thyroid status of Basenji in Australia. Aust Vet J 86: 429-434

Schaafsma, IA, Emst van, MG, Kooistra HS, Verkleij, CB, Peeters, ME, Boer P, Rijnberk, A, Everts, ME 2002: Excercise-induced hyperkalemia in hypothyroid dogs. Domest Anim Endocrinol 22: 113-125

Slob S, Klaren, PHM, Everts ME 2004: $\mathrm{Na}^{+}, \mathrm{K}^{+}$-ATP ase in skeletal muscle: Significance of exercise and thyroid hormones for development and performance. Muscle Development of Livestock Animals, CAB International, pp 137-156

Tučková M, Fialkovičová M, Baranová D, Bekeová E, Kozák M, Pálenik L 1995: Seasonal occurence and its effect on thyroid hormone concentrations in blood serum of German Shepherds, Dachshunds and their health status. Vet Med 40: 249-252 